the wheat from the chaff when it comes to online advice, videos give people who are considering self-treatment a better sense of what they're getting into, says Zaugg. "You don't need a lot of medical knowledge to perform certain procedures. In almost all cases, the main risks you run are infection or cutting into something you shouldn't, but that doesn't mean the knowledge should be inaccessible for anyone who wants to put the time and effort into learning. I think everything a doctor learns, your average intelligent person can learn without a degree."

It may be "quite reasonable" to train patients, particularly in remote locations, to remove their own stitches, but one should "never underestimate the ability of people to misinterpret rules or get them wrong," says Dr. Brian Goldman, an emergency room physician at Mount Sinai Hospital in Toronto, Ontario. "The first thing I'd want someone to tell me is how many stitches they had, because if they pulled out eight and are satisfied, when in fact there were nine, they could end up with an infection."

The popularity of medical how-to videos speaks to the "tremendous potential" that exists to teach patients to use health care services more appropriately, he adds. But in their current form, such videos typically fail to mention "anything about the potential complications" or take into account that "everything that seems simple may not be to everybody."

While Canadians are less likely than their American counterparts to "rifle their own medicine cabinets" rather than see a doctor for financial reasons, Goldman says wait times in Canada are motivation enough for some people to shirk professional care.

"A woman I know was scheduled for an appointment at an orthopedic clinic to have surgical pins removed from her foot. She arrived on time for her appointment at eight in the morning, and was kept waiting until four in the afternoon. At one point, she decided she couldn't wait any longer, so she pulled the pins out right there in the clinic and walked away. This is a smart person, and she was willing to do that."

A dearth of research tracking complications among patients who choose to skip the line and treat themselves at home makes it difficult to assess the health impact of open forum access to videos such as those featured in the "YouTube Medical School" series. Created by an orthopedic surgeon to provide practical examples of procedures to medical students "or anyone else who wants to study to be a doctor," the near 600 videos in the series have attracted some 1136850 views (www.youtube .com/user/surgicalgown).

However, a cursory search of patient narratives accompanying 2009 data compiled by the US Consumer Product
Safety Commission's National Electronic Injury Surveillance System reveals a litany of botched attempts to remove leg casts with paint thinner, moles with nail clippers, dry skin with razors and teeth with screwdrivers, among other do-ityourself medicine failures (www.cpsc .gov/cgibin/NEISSQuery/ExportFile.aspx ?FileName=/download/nss20027.tsv).

Most common are the "people who have a lump on their skin and are certain they have an abscess, so they squeeze it," putting themselves at risk of "particularly serious" blood-borne infections, says Goldman. Another category of doit-yourself enthusiast that Goldman frequently comes across in emergency rooms is "the patient who is convinced they have a foreign body, like a sliver, a metallic shard or a piece of glass or wood, which they've attempted to remove themselves. ... Sometimes I can remove it, sometimes I can't and sometimes there's nothing there at all."

While such cases are nothing new, the proliferation of medical how-to videos may lend a sense of false security to people who might otherwise have been on the fence about attempting a procedure at home, Goldman fears. "Suffice it to say, it happens in Canada, it happens in the United States, and I'd be very surprised if it doesn't happen in other countries, both developed and developing." — Lauren Vogel, CMAJ

CMAJ 2011. DOI:10.1503/cmaj.109-3812

\title{
"Do it yourself" births prompt alarm
}

A growing number of women are choosing to give birth without the assistance of doctors or midwives, provoked by dissatisfaction with modern obstetric care, fear of unnecessary medical intervention and a desire to reclaim birth as a private, natural act.

It's a choice the professionals say is fraught with peril. They fear the fledgling "freebirth" movement may undo gains in mother-infant mortality. The women, however, believe unassisted childbirth is emotionally and physically the safest option for themselves and their babies.
Some $33 \%$, or 8708 out of 26667 homebirths in the United States in 2007 were not attended by a physician or midwife, up from $30 \%$ in 2005 and $31 \%$ in 2006, according to the US Centers for Disease Control and Prevention (www.cdc.gov/nchs/data/nvsr/nvsr58 /nvsr58_24.pdf). Two-thirds of those deliveries attended by someone other than a physician or midwife in 2006 were reported as "planned" (www.cdc.gov /nchs/data/nvsr/nvsr58/nvsr58_11.pdf).

Canada lacks similar statistics, but a cursory search online turns up a surfeit of websites, forums, chat groups, guides and home videos dedicated to freebirth. Popular parenting website Mothering.com, for example, currently hosts more than 15000 active discussions on unassisted childbirth, or what members call "UC" (www.mothering .com/community).

It's a difficult trend to track with any certainty, not least because advocates of unassisted childbirth aim to avoid interaction with the medical system wherever possible.

While some women forgo prenatal care entirely, others orchestrate a "planned oops" or "accidental" unas- 
sisted birth to avoid confrontation with health care providers and the law.

Many are already mothers, wary after a bad experience with a doctor or midwife.

"My first son's hospital birth left something to be desired. We were both fine, but the doctor I had was terrible. When I became pregnant a second time, I sought out a midwife and while one of the women in the practice was great, the other really talked down to my husband and I, almost like we were children," explains Andrea Salcedo, a Calgary, Alberta-based mother who has since delivered two children unattended. "I was probably seven months pregnant when I decided I didn't want [that midwife] at my birth. I didn't want it to be a guessing game."

Others fear being coerced into medical procedures they're not comfortable with.

"There are some people who can go into the birthing room and put their foot down, but I know when I go into a doctor's office for an appointment, I get overwhelmed, let alone in a case where they're saying your baby might die," says Lia Joy Rundle, a Mazomanie, Wisconsin-based mother who delivered all three of her boys unattended. "I think it's easier to trust yourself if there's not another voice there. Having that other set of interests involved makes me uncomfortable."

Doctors and midwives bring their own timelines and expectations about how a delivery should proceed, and will err on the side of intervening in birth to protect themselves against litigation, says Laura Shanley, the Boulder, Colorado-based author of the book, Unassisted Childbirth, who has delivered five babies by herself. "I can see the position they're in, because if you don't deliver a perfect baby there's a chance you'll get sued, and there's this idea that if you've transferred someone to the hospital or done a c-section then you've done everything you could."

Births by cesarean section accounted for more than $25 \%$ of all hospital deliveries in 2004-2005, as compared with less than $18 \%$ a decade earlier, according to the Public Health Agency of Canada (www.phac-aspc.gc .ca/publicat/2008/cphr-rspc/factsheet

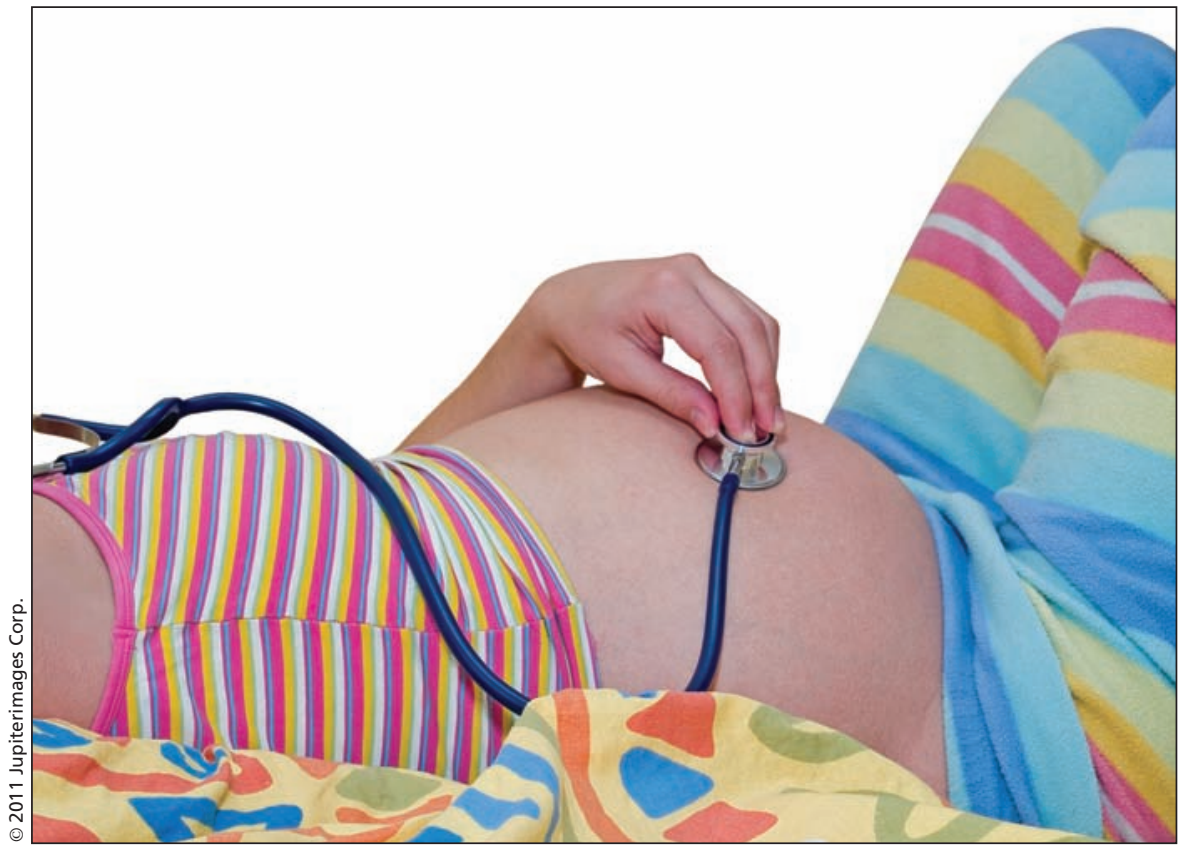

Some women prefer to put complete faith in their bodies and refer to complications as "variations of normal."

-fiche-eng.php). Significant variations in surgical rates among Canadian jurisdictions suggest some of these procedures "may not be appropriate or necessary," by recent Canadian Institute for Health Research estimates (www.cihi .ca/cihi-ext-portal/internet/en/document /health+system+performance/indicators /performance/release_16dec10). In 2008-2009, primary c-section rates ranged from a high of $23 \%$ of deliveries in Newfoundland and Labrador to a low of $14 \%$ in Manitoba.

With up to $15 \%$ of all births involving potentially fatal complications, however, "the evidence is overwhelmingly in favour of giving birth with a skilled attendant present," said Dr. Donald Davis, past president of the Society of Obstetricians and Gynaecologists of Canada, in a statement on freebirth (www.sogc.org /media/pdf/advisories/Release_freebirth _final_e.pdf).

Proponents of unassisted childbirth say it's all a matter of perspective. They prefer to view birth as a "spiritual, sexual experience, not an inherently dangerous medical event," says Shanley. "I trust the same intelligence that knows how to grow the baby from an egg and a sperm into a human being also knows how to complete the process."

Unnecessary intervention in birth is more often the cause of complications than a remedy, she adds. "People counting, measuring and managing birth into this controlled, manipulated act, it's no wonder women's bodies shutdown - the way anybody's would if someone kept interrupting them while they were trying to have sex, go to the bathroom or go to sleep."

Intervention should be the last resort, not a given, says Salcedo. "When I went to have my son's birth registered, one of the nurses asked why we didn't go to the hospital and my husband looked her in the eye and said: 'Because it wasn't an emergency'.'

The couple prepared for complications by reading books for first responders on how to deliver babies in emergency situations.

Others look for such information online.

"I had to assess what my personal risks were," says Rundle. "I'm a healthy young woman, so when people say that $15 \%$ of the time there's a complication, are they talking about women who have different medical histories than I have?"

Some women, like Shanley, prefer to put complete faith in their bodies and refer to complications as "variations of normal."

"There are going to be babies who die during an unassisted birth who may not have if there had been inter- 
vention, but there are also going to be babies who die because of interventions," she explains. "There's no way to ensure a successful birth every time. Sometimes a baby dies and that's just the way it is."

It's not a stance Shanley takes lightly, having lost a child to a congenital heart defect following an unassisted delivery, and been told by a coroner that the baby would have died even if she had gone to the hospital.

It's a difficult stance to counter, says Canadian Association of Midwives President Anne Wilson. "You can't say to a mum that $60 \%$ of all unassisted births result in complications where the baby dies because that kind of statistic doesn't exist. A lot of complications in childbirth are predictable and occur over time, but a few happen without warning, such as severe hemorrhage.
And if a woman doesn't have prenatal care, doesn't report the birth to the hospital, there's no way to know."

Globally, over 500000 women die each year from complications during childbirth, according to the Society of Obstetricians and Gynaecologists of Canada.

"Unassisted childbirth is unsafe period," said past vice president Dr. Vyta Senikas in the statement on freebirth. "The people advocating this as a mainstream option for women are tragically uninformed."

Midwives, however, are more "fuzzy" on the issue, says Wilson. The association has yet to take an official stance for fear of alienating women wary of intervention. "If someone came to us who was considering an unassisted birth we would want to keep that person engaged, build a relationship of trust and if they ended up going ahead with it, at least you're someone they can call if they get half way through a delivery and change their mind.'

Failing that, "some prenatal care is better than none," she adds.

The debate raises ethical questions of "autonomy versus beneficence" for midwives, Wilson says. "By the nature of what we do, we tend to look after people who don't want interventions. It would come down to individual choice in terms of how comfortable you are as a practitioner taking that person into your care."

For Shanley, however, unassisted childbirth is more a question of reproductive rights. "It's your body, your birth and your baby, so you should have the right to give birth however you want." - Lauren Vogel, CMAJ

CMAJ 2011. DOI:10.1503/cmaj.109-3820

\section{Comparison shopping for drugs}

A Web-based drug comparison tool developed by a nonprofit lobby for Americans over 50 will allow patients to price shop for prescription drugs as they would fridges or cars to ensure they're getting the best bang for their buck.

The Drug Savings Tool is the most recent in a suite of free health tools crafted by AARP (formerly the American Association of Retired Persons) to spark patient-doctor conversations about the cost, safety, efficacy and proper use of prescription drugs.

Developed in partnership with Consumer Reports, the tool lets patients compare the cost and efficacy of a drug to those of its brand name and generic competitors, and recommends a "best buy" based on clinical evidence. Patients can then print that information and share it with their doctor when discussing treatment options.

"Consumers are at a disadvantage in the health care market because they don't have access to credible and easyto-understand comparative information for drugs like they do for traditional products," says Doris Peter, manager of the Consumer Reports Health Ratings Center.

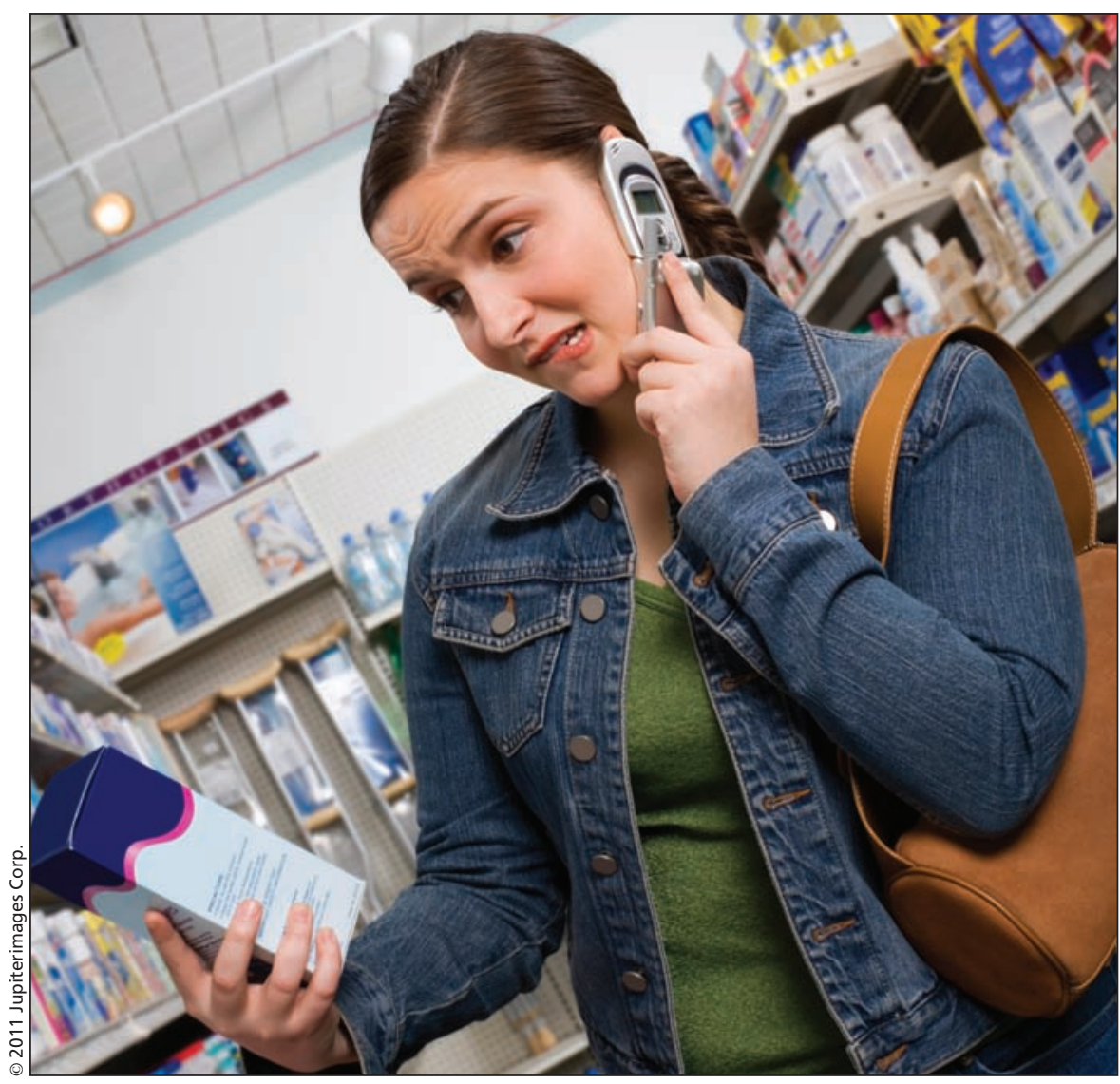

Some experts say that consumers and physicians are at a disadvantage in making drug choices because they don't have access to credible and easily digestible information about drug prices, efficacy and effectiveness. 